\title{
Invited Commentary: Promotion and Prevention in Youth Development: Two Sides of the Same Coin?
}

\author{
Jeanne Brooks-Gunn · Jodie Roth
}

Received: 18 February 2014/Accepted: 13 March 2014/Published online: 26 April 2014

(C) Springer Science+Business Media New York 2014

\begin{abstract}
This commentary uses the contributions of the 4-H Study of Positive Youth Development as a chance to reflect on the progress of the past two decades and suggest important tasks for the future. Meaningful advances in theory now set the stage for needed work on measurement, evaluation, and understanding of contextual processes. The commentary ends with a plea for an integration of the research and programmatic approaches of promotion and prevention in order to study youth development and implement youth programs.
\end{abstract}

\section{Introduction}

It is a pleasure to be able to write about this special issue of Journal of Youth and Adolescence which is dedicated to the tremendously valuable 4-H Study of Positive Youth Development conducted by Richard Lerner and his colleagues. These articles illustrate several themes in the study of youth. What the 4-H Study demonstrates, sometimes in quite vivid ways, is how far the field of positive youth development has come in the past two decades. Early conceptions were advanced in part to move away from what seemed like an exclusive focus on problem behavior and the "storm and stress" of the adolescent years. Scholars including Lerner, Hamilton, Benson, Eccles, and us, began thinking about youth as more than problems to be managed but as resources to be cultivated. This cadre of

J. Brooks-Gunn $\cdot$ J. Roth $(\square)$

Columbia University, New York, NY, USA

e-mail: jr328@columbia.edu researchers was joined by others including Blyth, Mahoney, MacBride, Tolan, Larson, Moore, Pittman, Spencer, and Damon, in focusing on the positive, not just on the negative, behaviors exhibited by teen-agers.

To do so, in many cases, required a rethinking of appropriate theoretical models, specification of constructs tapping into positive behavior, and development of measures of these constructs. It also required a focus on how such behaviors develop and change over time, requiring a longitudinal approach. And, focusing on the positive meant that the contexts in which youth develop had to be rethought, both in terms of which contexts were important and which contextual processes were operating. We had done a terrific job on the negative side of the ledger; it was time to do the same on the positive side.

In the first section of this essay, achievements in theory, measurement, developmental trajectories and contexts will be discussed, using the 4-H Study as an exemplar. The articles in this special issues highlight all four, given the design and purpose of the 4-H Study, as put forth by Lerner and his team. Woven into the section on progress in theory and research will be some suggestions for future work. The second section will consider, albeit briefly, implications for program implementation and practice. Such issues build on what might be termed the first phase of work on positive youth development, which the 4-H Study represents. Basic theory, measurement, context description, and change over time were needed as a grounding for considering programmatic efforts. The final section is a plea for integration of the two strands of youth development-promotion and prevention-into our theory, research, and programs. While positive youth development by its nature looks toward promotion, and problematic youth development considers prevention, we argue that the two approaches need to be tied together much more closely than in the past. 


\section{Progress in Theory and Research}

Theory development in positive youth development has in large part been done by Lerner (2006), who proposed an interactive, multi-contextual model, as elaborated in the articles in this issue. Other scholars also contributed to these efforts, including Larson, Hamilton, Damon, and Benson (Benson et al. 2006; Damon 2004; Larson 2000). At the same time, these researchers and others were struggling to define what constitutes positive youth development, coming up with a variety of constructs. For example, Lerner's group had the five and now six C's; Caring, Character, Competence, Confidence, Commitment, Connection. Benson's group and our group had slightly different but complementary constructs (Benson et al. 2006; Roth and Brooks-Gunn 2000, 2003).

Theoretical approaches plumbed developmental psychology for the most part, with little attention to theory from other fields, such as family sociology, behavioral economics, personality psychology, organizational psychology, educational psychology, and neuroscience. An agenda for the next decade would involve integrating thinking from these fields into positive youth development endeavors.

Measures were developed to tap constructs of positive youth development, with the 4-H Study being a notable example of such work. In some cases, measures were adopted from existing work with children and in other cases, from existing work with adults. What is needed now is some agreement on a set of measures that would be used across studies, so that cross-study comparisons with different samples can be done. At the moment, little consensus exists on measures. Of course, scholars will always use various measures in their studies; however, some consistency is desirable (an example is that most studies use, to tap childhood behavior problems, either the Child Behavior Check List or the Strength and Difficulties Questionnaire). The same is not true for Caring, Commitment, Confidence, Connection, and Character, although the situation is better for Competence, since many scholars use forms of Harter's Competence scales. Perhaps the next decade will see more consensus on what the strongest measures are (in terms of psychometrics as well as mapping onto constructs of positive development more specifically).

In addition to not knowing much about positive behaviors, we had no idea how such behaviors developed over time. Studies of trajectories of aggression and their correlates and consequences existed, but not comparable studies of the six C's. A few of the classic longitudinal studies made mention of positive behaviors, although often defined them as the absence of negative behaviors, a not very satisfactory definition. A notable exception was Werner's work in Hawaii, although even in her study, positive measures were scarce.
The 4-H Study set out to remedy this blank space in youth development by following a large group of youth from fifth grade through twelfth grade. The 4-H study drew respondents from 13 states, rather than just focusing on a city or county. Indeed, the multi-site longitudinal design is today considered the sina qua non of developmental research. But at the beginning of the 4-H Study, little had been done. One notable exception is Adolescent Health, which is a nationally representative sample of youth with schools as the frame. While longitudinal, it does not have the closely spaced data collection time points nor does it have positive behavior as a particular focus.

One of the greatest challenges confronting all of us studying positive youth development has been how to conceptualize and measure contexts. To be sure, previous research had focused on the various contexts in which youth find themselves. A robust literature existed on families, schools, and increasingly, neighborhoods (and peer groups which exist within schools and neighborhoods as well as families). However, the focus was usually on how these contexts were associated with the emergence of negative, not positive behaviors. A major strength of the 4-H Study is its focus on how various contexts can promote youth development. One of our challenges moving forward is to dig deeper into the processes within each setting that promote behavior.

As an example, early research on neighborhoods considered demographic characteristics associated with Census tracts and police districts. The processes underlying these characteristics were not measured explicitly. Now, however, attention is paid to processes such as social networks, collective efficacy, cynicism as well as resources such as parks, community programs, and health clinics. These processes are being linked to youth outcomes, but for the most part looking at negative behaviors. Similar work needs to be done within contexts for positive development.

\section{Implications for Positive Youth Development Programs}

The guiding principles underlying positive youth development have also been profitably applied to youth programs. In fact, the rise in programs focusing on positive youth development occurred as part of the positive youth development movement (Roth et al. 1998). The 4-H Study was unique for its time in including youth who were participating in youth programs as well as youth who were not (i.e., recruitment was done in programs and schools). While the focus of the 4-H Study is not primarily on youth programs (although analyses have examined program participation), evaluative research has had as its primary focus the experiences of youth in various types of youth programs. The emerging evaluation literature has quite a few 
limitations, though, which we have recently discussed (Roth and Brooks-Gunn, in press).

Perhaps the largest problem is that consensus does not exist on exactly what a positive youth development program is (our definition from 1998 is as relevant today as it was then, and is regrettably quite general). Do programs run by schools count (sport teams, theatre, debate, and so on)? Should distinctions be made between such programs that are run by the school and those run by community organizations? Are there differential benefits to programs in these different settings? How do we treat programs that have multiple elements (i.e., a community service element, a sports team, an art program)? Do programs need to include civic responsibility as one of their goals to be a positive youth development program?

Another set of issues has to do with the quality of the program as well as the staff. Attempts have been made to develop rating systems for youth programs, akin to those used to assess quality of preschool programs (much of this work was funded by the W. T. Grant Foundation). More needs to be done. Training of adults who work with youth is also needed. How programs are implemented and how they evolve over time also is unexplored. A related issue has to do with what elements of programs are the most important.

Finally, most of the positive youth development evaluation work is not experimental or even quasi-experimental, making it difficult to estimate the efficacy of such programs (see Roth and Brooks-Gunn 2003, in press, for a discussion). The descriptive studies have improved immensely in the past decade, with almost all involving longitudinal analyses and with some including controls for characteristics (and ideally behavior) prior to the program experience. More attention needs to be given to attrition, as many youth drop out of youth programs and to intensity, as many youth attend programs sporadically. If we have learned anything from the early childhood education evaluations, it is that amount of time spent in a program matters such that low intensity programs yield small or non-existent benefits.

This very brief list gives an idea of the enormous challenges that exist for positive youth development programs. We are somewhat surprised that the evaluation research in positive youth development has not developed further in the past two decades, especially in light of the advances made in theory and research.

\section{Integration of Promotion and Prevention}

Positive youth development has been championed by talented scholars for almost two decades now. The growth of research, and sophisticated research at that, has been larger than any of us would have dreamed in the mid 90's. Obviously, we are all thrilled. With success, though, comes a time for reflection about the next decade of work. Writing an essay on the influential and ground-breaking 4-H Study provided us an opportunity to do so.

We wonder if it is time to declare victory. After all, youth are no longer portrayed in a largely negative light. Doing well in the second decade of life used to be seen as not having problems-not graduating from high school or falling behind in school, not having become pregnant, not having exhibited delinquency. Now, doing well includes much more-caring, connection, commitment, and the like. Perhaps we can now use the more inclusive termyouth development-which encompasses both promotion of the positive and prevention of the negative.

In the first decade of life, we talk about child development, not positive child development and problematic child development. Can we now do the same for the second decade of life? It would allow for an integration of research approaches as well as programmatic approaches. In both cases, considering positive and negative behaviors and promotion and prevention programs simultaneously provides an opportunity to re-think theory as well as policy. And, implicitly, many research studies measure both types of behavior just as many programs are emphasizing both prevention and promotion. Additionally, prevention approaches are much better known and developed (Greenberg and Lippold 2013). Finally, prevention programs for youth is getting international recognition (Catalano et al. 2012). The integration of prevention and promotion approaches may have application beyond the US In brief, it might be time to use the more encompassing terms of youth development and youth programs.

Acknowledgments Thanks go to all the scholars who nurtured the emerging topic of positive youth development, the graduate students and post-doctoral fellows who joined in the study of positive youth development (and moved it forward), the foundations who promoted research on positive youth development (most notably the W. T. Grant Foundation and the Templeton Foundation), and most of all, to the youth who exhibit positive development.

Author contributions J.B.G. and J.R. contributed equally the framing and writing of this commentary.

\section{References}

Benson, P. L., Scales, P. C., Hamilton, S.F., \& Semsa, A. Jr. (2006). Positive youth development: Theory, research, and applications. In W. Damon \& R. Lerner (Eds.), Handbook of child psychology: Volume 1. Theoretical models of human development (6th Ed, pp. 894-941). Hoboken, NJ: Wiley.

Catalano, R. F., Fagan, A. A., Gavin, L. E., Greenberg, M. T., Irwin, C. E., Jr, et al. (2012). Worldwide application of the prevention science in adolescent health. Lancet, 379, 1653-1654.

Damon, W. (2004). What is positive youth development? Annals of the American Academy of Political and Social Science, 591, 13-24. 
Greenberg, M. T., \& Lippold, M. A. (2013). Promoting healthy outcomes among youth with multiple risks: Innovative approaches. Annual Review of Public Health, 34, 253-270.

Larson, R. W. (2000). Towards a psychology of positive youth development. American Psychologist, 55, 170-183.

Lerner, R. M. (2006). Developmental science, developmental systems and contemporary theories. In W. Damon \& R. M. Lerner (Eds.), Handbook of child psychology; Volume 1. Theoretical models of human development ( $6^{\text {th }}$ Ed., pp. 1-17). Hoboken, NJ: Wiley.

Roth, J. L. \& Brooks-Gunn (in press). Evaluating youth development programs: Recent progress and areas for improvement. Journal of Applied Developmental Science.

Roth, J. L., \& Brooks-Gunn, J. (2000). What do adolescents need for healthy development?. Implications for youth policy: Social Policy Report, Society for Research in Child Development. 14.

Roth, J. L., \& Brooks-Gunn, J. (2003). What exactly is a youth development program? Answers from research and practice. Applied Developmental Science, 7, 94-111.
Roth, J., Brooks-Gunn, J., Murray, L., \& Foster, W. (1998). Promoting healthy adolescents: Synthesis of youth development program evaluations. Journal of Research on Adolescence, 8, $423-459$.

Jeanne Brooks-Gunn is the Virginia and Leonard Marx professor of Child Development at Columbia University, Teachers College, and the College of Physicians and Surgeons. She directs the National Center for Children and Families (www.policyforchikdren.org).

Jodie Roth is a research consultant with the National Center for Children and Families, Teachers College, Columbia University. She received her doctorate in Education and Psychology from the University of Michigan. Her major research interests include youth development and afterschool activities. 